\title{
PUBLIC INFORMATION AND TERRITORY ESTABLISHMENT IN A LOOSELY COLONIAL RAPTOR
}

\author{
Fabrizio Sergio ${ }^{1}$ And Vincenzo Penteriani \\ Department of Applied Biology, Estación Biológica de Doñana, C.S.I.C., Avda. de María Luisa s/n., Pabellón del Perú, \\ Apdo 1056, 41013 Seville, Spain
}

\begin{abstract}
Evidence is increasing that animals may select habitats using direct cues (direct assessment hypothesis) and indirect cues, such as cuing on the presence of conspecifics (conspecific attraction hypothesis) and on their productivity in the previous year (public information hypothesis). We tested such hypotheses by studying the establishment of new territories (by inexperienced individuals) in the Black Kite (Milvus migrans), a long-lived, loosely colonial raptor, previously shown to exploit public information for foraging and dispersal decisions. All three hypotheses (direct assessment, conspecific attraction, and public information) were simultaneously supported; new territories were established on the basis of a complex system of integrated, direct and indirect cues, collected in the current and previous year. Exploitation of public information was allowed by the patchiness and moderate temporal predictability of breeding success (the information cue). Establishment of new territories near conspecifics involved a breeding cost for nearby previous residents, suggesting that conspecific cuing may be a form of information parasitism, at least in our system. Conspecific cuing affected nest spacing and population trend; mean nest spacing declined with colony size, while higher colony and population-level productivity in one year were followed by higher recruitment of new breeders in the following year, despite the delayed maturity of the species. All results were consistent with recent predictions by theoretical models.

Key words: Black Kite; conspecific attraction and cuing; habitat quality and selection; Milvus migrans; performance based conspecific attraction; public information; settlement on territory; territory establishment and quality.
\end{abstract}

\section{INTRODUCTION}

On a year-to-year basis, the growth of a breeding population will be determined by the balance between the number of newly established breeding sites and the number of abandoned ones. Therefore, an understanding of the factors promoting site establishment and abandonment is fundamental for population ecology and conservation. Although there has been much interest in factors driving site abandonment (e.g., Liberatori and Penteriani 2001, Sergio et al. 2004b), less attention has been devoted to the establishment of new breeding sites. Individuals establishing new territories are likely to employ decision rules similar to those reported in habitat selection and settlement studies, including direct assessment of habitat quality and utilization of other indirect cues (Stamps 1987, Danchin et al. 1998, 2001). Among the latter, increasing evidence is supporting the idea that animals may employ the presence and abundance of conspecifics (conspecific attraction hypothesis), or their breeding success in the previous year (public information hypothesis, or performance based conspecific attraction hypothesis) to

Manuscript received 16 January 2004; revised 7 June 2004; accepted 19 July 2004; final version received 9 September 2004. Corresponding Editor: J. R. Walters.

${ }^{1}$ E-mail: fabrizio.sergio8@tin.it gather information on habitat quality and settle accordingly (review in Danchin et al. 2001, Doligez et al. 2003).

The conspecific attraction hypothesis predicts that individuals will prefer sites nearer to conspecifics compared to random suitable sites (Stamps 1994). The performance based conspecific attraction hypothesis assumes that breeding success is spatially patchy and temporally predictable, and predicts that: (1) individuals will choose sites based on the breeding success of nearby conspecifics in the previous year(s); and (2) patches with higher than average breeding success will recruit more new breeders in following years, leading to a higher multiplication rate (Danchin et al. 1998, Reed et al. 1999, review in Danchin et al. 2001). Despite many studies on conspecific attraction in reptiles, mammals, birds, and invertebrates (review in Reed et al. 1999), performance based conspecific attraction has been investigated in only a handful of species (review in Danchin et al. 2001, Doligez et al. 2002, Serrano et al. 2001). Current evidence suggests that conspecific cuing should be particularly expected in naïve individuals of gregarious, long-lived species, especially those which benefit by breeding at high density through social facilitations (Stamps 1988, 1994, Boulinier and Danchin 1997, Muller et al. 1997, Reed et al. 1999, Danchin et al. 2001). 
Here, we: (1) test whether Black Kites (Milvus migrans) establish new territories on the basis of conspecific cues; (2) examine the potential costs of new territory establishment for previous residents; and (3) investigate the population consequences of conspecific cuing. The Black Kite is a medium-sized, facultatively colonial, opportunistic raptor (Hiraldo et al. 1990). It is a good model for testing hypotheses of conspecific attraction because: (1) it is loosely colonial and gregarious in the breeding and nonbreeding period (Bustamante and Hiraldo 1990, Sergio and Boto 1999); (2) it is long-lived, with age of first reproduction at threefour years (Blas 2002), which prevents confounding effects in tests of performance based conspecific attraction (Boulinier and Lemel 1996); this is because the establishment of a new territory on the basis of conspecific productivity in the previous year can not be caused by simple philopatry; (3) conspecific attraction has been shown to influence kite natal and breeding dispersal in previous studies (Forero et al. 1999, 2002); (4) newly established territories are usually occupied by inexperienced individuals (Sergio and Newton 2003; F. Sergio, unpublished data), which are more likely to cue on conspecifics (Muller et al. 1997); (5) in the Alps, where this study was conducted, kites nest on cliffs facing large lakes, where they forage for fish through local enhancement mechanisms (Sergio 2003a), implying potentially higher social facilitations at higher densities and potential benefits associated with settling near conspecifics, especially for inexperienced individuals (Stamps 1988, 1994); (6) in the Alps, kites' density and productivity are tightly related to food availability and risk of predation by Eagle Owls (Bubo bubo; Sergio et al. 2003a-d), both of which determine steep gradients of habitat quality, relatively predictable from one year to the next, but not necessarily easy to assess directly (especially predation risk; Sergio et al. 2003a, $c$ ); this may promote utilization of indirect cues; and (7) on return from migration, the time window for settlement on territory is short (only 10-15 days, Sergio 2003a) and productivity declines with laying date (Sergio 2003b), constraining time for direct habitat assessment and favoring the utilization of indirect cues (Danchin et al. 2001).

\section{Methods \\ Study areas}

Black kites were monitored between 1992 and 2003 in seven areas in the Italian Alps (Appendix A): Lake Maggiore (surveyed from 1996 to 2000), Lake Lugano (1992-2003), Lake Como (1996-2000), Lake Iseo (1996-2000), Lake Idro (1997-2000), Lake Garda (1996-2000), and Sarca Valley (1997-2003). The lake areas had mountain slopes covered by extensive woodland and much aquatic habitat. The Sarca Valley area was characterized by forested mountain slopes and wide, intensively cultivated valley floors with a few small lakes (details in Sergio et al. 2003b,c).

\section{Field procedures}

Black kites were censused through multiple surveys conducted every 2-5 days between 5 and 25 April each year (Sergio and Newton 2003). Locations of territorial pairs and their nests were detected by watching territorial displays and nest material transfers. For accessible nests, contents were checked when chicks were 40-45 days old to record the number of young raised (details in Sergio and Boto 1999). In our areas, the main predator of kite adults and nestlings is the Eagle Owl (Sergio et al. 2003a,c). Therefore, between 1996 and 2000 we located and counted Eagle Owls in all study areas (details in Marchesi et al. 2002 and Sergio et al. 2004a).

\section{Assumptions, predictions and statistical analyses}

Based on previous work on conspecific cuing (review in Danchin et al. 2001), we tested the following assumptions: (1) breeding success is spatially patchy, and (2) temporally auto correlated; we also tested the following not mutually exclusive predictions: (1) kites establish new territories on the basis of habitat quality; (2) of conspecific attraction; or (3) of performance based conspecific attraction; (4) the establishment of a new territory imposes a cost for its neighbor; (5) settling near a higher quality territory provides a higher future breeding benefit for the new breeder; (6) at the colony or whole population level, multiplication rate (number of territories in year $t$ /number of territories in year $t-1$, Danchin et al. 1998) is related to the mean breeding success in the previous year.

Assumption 1 has been tested in previous publications (see Results). Assumption 2 and predictions 5 and 6 were tested by means of parametric and nonparametric correlations and multiple regression (Sokal and Rohlf 1981). Prediction 4 was tested by comparing, by means of a matched-pairs $t$ test (Sokal and Rohlf 1981): (1) the breeding success of a territory before and after the establishment of a new territory in its immediate neighborhood; and (2) the breeding success of a territory that acquired a new neighbor with the breeding success of a territory (hereafter defined as "control territory") that was equally successful in the previous year but which did not acquire a new neighbor. Predictions 1, 2, and 3 were tested by means of two stepwise logistic regressions (Tabachnick and Fidell 1996), which compared newly established territories $(n=56)$ with an equal number of: (1) random locations classified as suitable for Black Kites by a previously published logistic nest-site selection model (Sergio et al. $2003 a, d)$; and (2) random, vacant territories. To select the latter, for each newly established territory in year $t$, we chose one territory occupied before year $t$, but not occupied during year $t$ (i.e., a suitable location currently available for occupation). Furthermore, if a num-

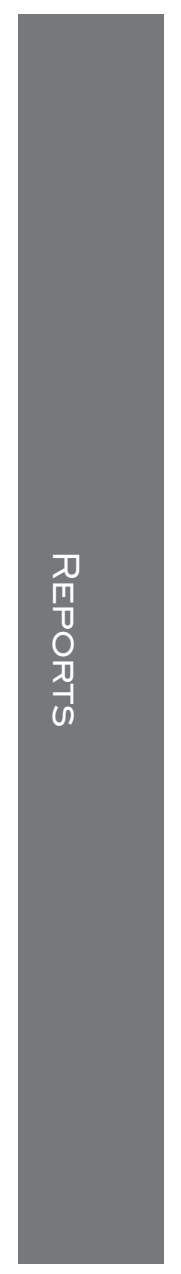


ber $X$ of newly established territories were located within colonies, we ensured that $X$ random locations or random vacant territories were also within colonies, so as to control for the confounding effect of coloniality (e.g., in a colonial species with a clumped distribution, random locations are likely to be far from colonies, biasing analyses of conspecific attraction). This also allowed us to test whether conspecific attraction acted within colonies. Therefore, the two logistic models allowed us to investigate the factors by which kites chose certain locations over other suitable and available ones, while controlling for coloniality. Explanatory variables entered in the logistic models included: (1) study area (categorical variable); (2) nearest neighbor distance (NND) in current year (year $t$ ); (3) breeding success of the current nearest neighbor in year $t-1$; (4) number of nests in the colony in year $t$; (5) number of nests within $400 \mathrm{~m}$ in year $t$; (6) number of nests within 400 $\mathrm{m}$ in year $t-1$; (7) mean breeding success within 400 $\mathrm{m}$ in year $t-1$ (excluding the productivity of the nearest neighbor). Variables number 3, 6, and 7 were also collected for year $t-2$. Further variables estimated territory quality, based on previous work on our populations (Sergio and Newton 2003, Sergio et al. $2003 a-d)$. (8) distance to the nearest wetland (optimal foraging habitat); (9) food availability, expressed as percentage of wetlands within $1 \mathrm{~km}$ of the nest multiplied by their productivity, as measured by their phosphorus content (details in Sergio and Newton 2003, Sergio et al. 2003a, $b$ ); and (10) distance to the nearest Eagle Owl nest. The last three variables were also collected for the nearest neighbor of each newly established territory or random location. The measure of 400 $\mathrm{m}$ around territories was used because, given local topography, most kite pairs are likely to interact with and be directly visible to other pairs within $400 \mathrm{~m}$ of their nest (analyses with different radii gave similar results). Breeding success was measured as the number of young fledged by a pair and expressed as a deviation from the yearly mean of each population, following Perrins and Jones (1974) and Schiek and Hannon (1992), so as to control for previously demonstrated spatiotemporal variations in productivity (Sergio and Boto 1999, Sergio et al. 2003b).

Because new territories could be established by philopatric birds returning to natal areas 3-5 years later (Blas 2002, Forero et al. 2002, Doligez et al. 2003), we re-ran the logistic models described previously by adding to the explanatory variables, for each territory newly established in year $t(n=35)$, the mean breeding success within $400 \mathrm{~m}$ in year $t-3, t-4, t-5,(t-$ $3)+(t-4)$, and $(t-3)+(t-4)+(t-5)$, following Danchin et al. (1998). Because such analysis required a long study period, it was conducted using only data from the Lake Lugano population (the only one monitored for 12 years).

Unless otherwise specified, all analyses were conducted on the largest available sample, by pooling data from all study areas for the years 1997-2000, when all populations were simultaneously surveyed. In all analyses, each territory is always used once, so as to avoid pseudo-replication. All random locations were generated by means of the extension "Animal Movement" of the GIS software ArcView (Hooge and Eichenlaub 1997). All logistic regressions were run through a backward stepwise generalized linear model (GLM) procedure (GLIM 4.0), following Crawley (1993): all explanatory variables were fitted to the model, extracted one at a time from such maximal model and the associated change in model deviance assessed by a $\chi^{2}$ test. Such procedure allows to control for collinearity (Crawley 1993:192-193). Prior to parametric tests, variables were $\log _{e^{-}}$, square-root, or arcsine square-root transformed, if necessary, to achieve a normal distribution. For all analyses, means are given $\pm 1 \mathrm{SE}$, tests are two-tailed, and statistical significance was set at $\alpha$ $\leq 0.05$. When multiple tests were performed on the same data set, the sequential Bonferroni correction was used to adjust the significance level (Rice 1989).

\section{RESULTS}

\section{Assumption 1: Habitat quality is patchy}

We have previously shown that, independently of year, kite productivity varies among populations, colonies, and territories (Sergio and Boto 1999, Sergio and Newton 2003, Sergio et al. 2003b). Therefore, we consider that assumption 1 was met.

\section{Assumption 2: Habitat quality is temporally autocorrelated}

Breeding success ( $\log _{e}$ transformed) of each territory was autocorrelated from one year to the next (1997$1998, r=0.66, N=48, P=0.002 ; 1998-1999, r=$ $0.36, N=52, P=0.027 ; 1999-2000, r=0.46, N=$ $42, P=0.008)$, but not over time lags of two or three years $(r \leq 0.31, P \geq 0.11)$. Assumption 2 was met.

\section{Predictions 1-3: Territory establishment in relation to habitat quality and conspecific cuing}

Compared to random suitable locations, newly established territories were nearer to wetlands and nearer to a conspecific that had a higher breeding success in the previous year (Table 1a, Fig. 1). Compared to random vacant territories, newly established ones had a nearest neighbor with a higher productivity in the previous year and neighbors within $400 \mathrm{~m}$ with a higher mean productivity in the previous year (Table 1b, Fig. 1). Similar conceptual results were obtained when incorporating the potential effect of philopatry: (1) compared to random suitable locations, newly established territories were nearer to wetlands, had a higher density of conspecifics within $400 \mathrm{~m}$ in the current year, a nearest neighbor with a higher productivity in the previous year, and neighbors within $400 \mathrm{~m}$ with a higher mean productivity in the previous year (Table 1c); and 
TABLE 1. GLM logistic regressions testing the effect of habitat quality and conspecific cuing on the establishment of new territories by Black Kites (Italian pre-Alps, 1992-2003).

\begin{tabular}{|c|c|c|c|c|}
\hline $\begin{array}{l}\text { Random locations or vacant territories } \\
\text { compared with newly established territories }\end{array}$ & $\begin{array}{c}\text { Parameter } \\
\text { estimate } \pm 1 \mathrm{SE}\end{array}$ & $\chi^{2}$ & $P$ & $\begin{array}{c}\text { Deviance } \\
\text { explained } \\
\quad(\%)\end{array}$ \\
\hline a) Random suitable locations $(N=112)$ & & & & 36.2 \\
\hline Distance to the nearest wetland $\dagger$ & $-0.71 \pm 0.22$ & 12.4 & $<0.001$ & \\
\hline Distance to the nearest neighbor $\dagger$ & $-0.80 \pm 0.27$ & 5.4 & $<0.05$ & \\
\hline Productivity of nearest neighbor in previous year & $4.96 \pm 1.09$ & 16.9 & $<0.001$ & \\
\hline Constant & $1.80 \pm 2.13$ & & & \\
\hline b) Random vacant territories $(N=112)$ & & & & 37.7 \\
\hline Mean productivity within $400 \mathrm{~m}$ in previous year $\dagger \S$ & $2.99 \pm 1.01$ & 6.1 & $<0.05$ & \\
\hline Productivity of nearest neighbor in previous year $\dagger$ & $6.55 \pm 1.22$ & 29.8 & $<0.0001$ & \\
\hline Constant & $-7.47 \pm 1.53$ & & & \\
\hline c) Random suitable locations $(N=70) \|$ & & & & 70.8 \\
\hline Distance to the nearest wetland $\dagger$ & $-1.76 \pm 1.02$ & 7.09 & $<0.05$ & \\
\hline No. nests within $400 \mathrm{~m}$ in previous year & $0.86 \pm 0.31$ & $9.2 \pi$ & $<0.001$ & \\
\hline Mean productivity within $400 \mathrm{~m}$ in previous year $\$ \S$ & $3.16 \pm 2.60$ & $5.84 \pi$ & $<0.05$ & \\
\hline Productivity of nearest neighbor in previous yeart & $12.02 \pm 5.35$ & 64.9 II & $<0.0001$ & \\
\hline Constant & $13.64 \pm 7.91$ & & & \\
\hline d) Random vacant territories $(N=70) \|$ & & & & 39.0 \\
\hline Productivity of nearest neighbor in previous year $\dagger$ & $2.99 \pm 0.72$ & 9.3 & $<0.001$ & \\
\hline Constant & $-1.82 \pm 0.51$ & & & \\
\hline
\end{tabular}

Note: Regressions include binomial errors and a logit link function (Crawley 1993).

$\dagger \log _{e}$ transformed.

† Square-root transformed.

$\S$ Excluding data on the productivity of the nearest neighbor.

$\|$ Model re-run on data from the Lake Lugano population to test the potentially confounding effect of philopatry (see Methods).

II Tested by means of an $F$ test, after correcting for overdispersion (Crawley 1993:278-279).

(2) compared to random vacant territories, newly established ones had a nearest neighbor with a higher productivity in the previous year (Table 1d). Therefore, predictions 1-3 were supported.

\section{Prediction 4: Conspecific cuing implies a cost for previous residents}

Compared to the previous year, there was a decline in the productivity of pairs that had as a nearest neighbor a newly established territory (number of fledged young in year before establishment, $1.11 \pm 0.10$ fledged young, mean $\pm 1 \mathrm{SE}$; year of new territory establishment, $0.52 \pm 0.11$ fledged young; matchedpairs $t$ test, $\left.t_{55}=-3.55, P=0.004\right)$. Furthermore, pairs that acquired a new neighbor had a lower productivity than control pairs $(0.52 \pm 0.11$ and $0.88 \pm 0.11$ fledged young, respectively, matched-pairs $t$ test, $t_{55}=-2.82$, $P=0.007)$. Prediction 4 was supported.

\section{Prediction 5: Settling near a higher quality territory implies a higher future breeding benefit}

Most newly established territories failed to breed in their first year and their productivity increased during the first four years of territory occupation (Appendix B). We fitted the variables that were predictors of territory establishment (in the logistic models of predictions $1-3)$ to a stepwise multiple regression with the mean territory productivity in the first four years after establishment as a dependent variable ( $\log _{e}$ transformed). The only variable which entered the model was the distance of the territory to the nearest wetland
$\left(B=-0.17 \pm 0.07, t=-2.5, P=0.022, R^{2}=0.25\right)$.

Prediction 5 was partially supported.

\section{Prediction 6: Multiplication rate is related to the} mean breeding success in the previous year

The fact that new territories were established near conspecifics meant that, as colonies grew, they became more densely packed. Data from five colonies (with always $\geq 3$ territories) monitored for 12 years showed a consistently negative relationship between colony size and mean within-colony NND (in all cases $r_{\mathrm{S}} \leq$ $-0.67, N=12, P \leq 0.018)$.

Spatial variations among 14 colonies showed that colony multiplication rate was positively related to the previous year colony productivity, but the relationship was significant in only one of the years (1997-1998, $r_{\mathrm{S}}=0.67, P=0.024 ; 1998-1999, r_{\mathrm{S}}=0.45, P=0.22$; 1999-2000, $\left.r_{\mathrm{S}}=0.10, P=0.97\right)$. Similarly, colony multiplication rate was positively but not significantly related to the previous year productivity within each of five colonies monitored for 12 years in the Lugano area (in all cases, $r_{\mathrm{S}} \leq 0.58, N=11, P \geq 0.30$ ). Finally, at the population level, the correlation between population multiplication rate and the previous year's productivity was positive but not significant for both spatial variations among the seven study areas (1997$1998, r_{\mathrm{S}}=0.44, P=0.66 ; 1998-1999, r_{\mathrm{S}}=0.04, P$ $\left.=0.94 ; 1999-2000, r_{\mathrm{S}}=0.51, P=0.48\right)$ and for temporal variations along the 12 years of study of the Lake Lugano population $\left(r_{\mathrm{S}}=0.15, N=11, P=0.67\right)$. Therefore, all spatiotemporal relationships were con- 


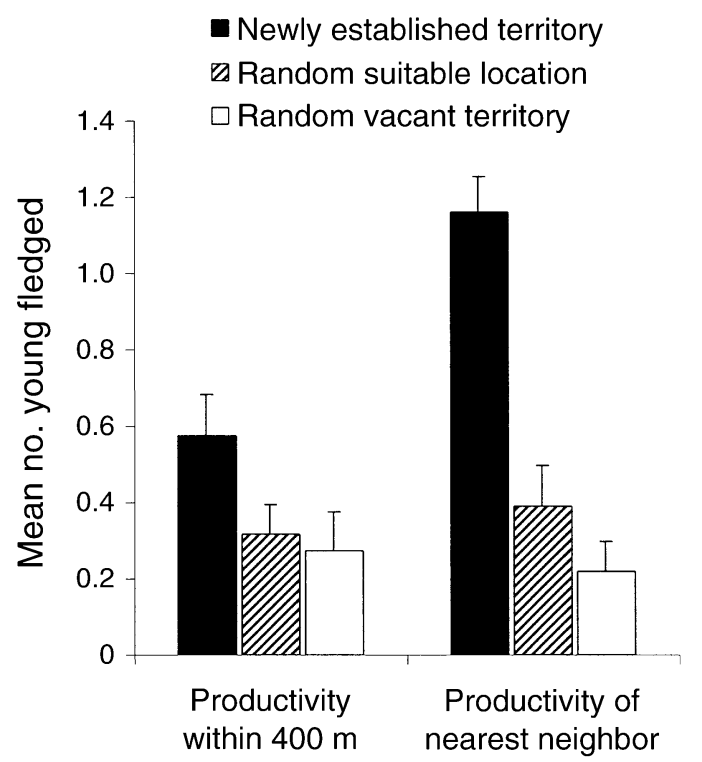

FIG. 1. Productivity (mean $\pm 1 \mathrm{SE}$ ) in the previous year of the nearest neighbor or of the pairs within $400 \mathrm{~m}$ of: 56 newly established Black Kite territories, 56 random locations potentially suitable for kite nesting (as predicted by a logistic nest-site selection model [Sergio et al. 2003d]), and 56 random, vacant territories. Productivity was measured as the number of young fledged by a pair and was expressed as a deviation from the yearly mean of each population, to control for previously demonstrated spatiotemporal variations in productivity (Sergio and Boto 1999, Sergio et al. 2003b), following Perrins and Jones (1974) and Schiek and Hannon (1992). However, to avoid negative numbers in the graph, we have added to each mean value the grand mean of productivity for all the study years and populations.

sistently in the expected direction, both at the colony level and at the population level, but rarely significant (binomial test, $P=0.0004$ ). Prediction 6 was only weakly supported.

\section{DISCUSSION}

All assumptions of the public information hypothesis were met: productivity varied spatially and was temporally autocorrelated, though only over a short time span (one year). This made information collected in the previous year available for site assessment and, in agreement with predictions, patch productivity in the previous year was a predictor of new territory establishment. The above result fitted the theoretical-modeling prediction that use of public information for habitat selection should be selected for in moderately predictable environments (Doligez et al. 2003). In particular, kites seemed to cue mostly on just one pair, their future nearest neighbor, whose previous year's productivity consistently entered all the logistic models. This suggests that cuing targets and decisions may be more simple than previously thought, even within large colonies. Cuing on conspecific productivity may be a particularly expected strategy in our system because, besides being temporally predictable, territory-level pro- ductivity varies with food availability and predation risk (Sergio and Newton 2003, Sergio et al. 2003a, $c$, $d$ ) and thus integrates multiple components of habitat quality (Danchin et al. 2001), some of which would be probably difficult or time consuming to assess directly. For example, predation risk would be an elusive component, because the predator is nocturnal (i.e., not easily visible) and may affect kite productivity even when nesting $>2-3 \mathrm{~km}$ away (Sergio et al. 2003a). Furthermore, because kites observe conspecific behavior to detect locations and time-windows favorable for foraging (Sergio 2003a; F. Sergio, unpublished data), successful breeding may be further used as a proof of foraging capability (high quality territories have high productivity and high rates of prey delivery to the nest; Sergio and Newton 2003, Sergio et al. 2003c). Settling near a successful forager could thus involve higher foraging opportunities through information parasitism and local enhancement (e.g., Green 1987, Buckley 1997). Such social facilitation would enhance the benefit of both conspecific attraction and performance based conspecific attraction and would create a scenario in which both breeding and foraging habitat selection are mediated by the opportunistic exploitation of public information (Valone 1989).

Productivity is likely to convey reliable but not necessarily perfect information on habitat quality (e.g., Reed et al. 1999). For example, for intermediate levels of environmental predictability, theoretical models suggest that direct assessment of habitat quality may be sometimes a more efficient strategy than employing public information, especially when direct assessment is based on easy to assess measures (Doligez et al. 2003). In agreement with such argument, new territories were also established on the basis of a direct, simple measure of habitat quality, i.e., the distance to the nearest wetland.

Finally, there was also evidence of territory establishment based on simple conspecific attraction (local density of conspecifics in current and previous year), which may have further refined the quality of the other information gathered and been favored by social facilitation associated with higher local densities (e.g., foraging facilitation cited above, higher predator and intruder protection, reviewed in Stamps 1988, 1994). Therefore, overall, territory establishment was based on a complex, integrated system of direct and indirect cues. This is once again in agreement with, and extends to the individual level, recent theoretical predictions, which state that different assessment strategies may often coexist within the same population (Doligez et al. 2003). Furthermore, the fact that the conspecific attraction cues involved information collected in both the previous and current year suggests that individuals may update and fine-tune previously collected information on the basis of currently available cues (e.g., current patch density of conspecifics), as previously suggested by Reed et al. (1999). 
Conspecific cuing involved a cost for previous residents. Typically, very high productivity of a territory (or subsector of a colony) in one year was followed by settlement of a new pair nearby in the following year. This was usually accompanied by a low NND and much fighting with the owners of the previously existing territory (up to $80 \%$ of the time spent in intraspecific interactions in quantitative time budgets; F. Sergio, unpublished data), probably leading to the observed productivity decline by the earlier residents. The latter typically won all direct confrontations with their new neighbors, but these still managed to settle through persistence, a common occurrence in territorial systems (review in Stamps 1994). Such cost would make performance based conspecific attraction a form of information parasitism. Note that attraction to conspecifics and social facilitation at higher densities are not in contradiction with subsequent density-dependent competition (e.g., Stamps 1994). Such a scenario has interesting repercussions for population dynamics because it could generate one-year-lag positive density dependence and two-year-lag negative density dependence even in a species with delayed maturity.

At the population level, spatiotemporal predictions of the public information hypothesis were mostly not significant, though consistently in the predicted direction. More analyses and a longer time series will be required to reach firmer conclusions. However, we have previously shown that, along an inland-wetland gradient of habitat quality, a higher productivity in the wetland portion of the gradient in a year $t$ is followed by a density increase in the same portion of the gradient in year $t+1$ (Sergio et al. 2003c), i.e., portions of the gradient with above average breeding success act as magnets for territory establishment the following year. Given the delayed maturity of the species, such a result strongly supports the idea of a population effect of habitat selection mediated by public information.

\section{Conservation implications}

Conspecific cuing usually results in a clumped distribution with much suitable but empty habitat, leading to higher risks of extinction due to stochastic events (Stamps 1988, Ray et al. 1991). Therefore, vulnerable species employing conspecific cuing, such as Black Kites, should be afforded additional conservation effort. On the positive side, the idea that individuals may integrate many assessment strategies, including direct assessment, suggests that they may potentially retain the capability to colonize new patches, even if free from conspecifics, if necessary (e.g., in a population recovering from a crash). On the other hand, conspecific cuing may slow range expansion of recovering or reintroduced species, as observed for example in the reintroduction of Red Kites (Milvus milvus) in the United Kingdom, where newly established pairs mostly saturate the density within the already occupied range, which slowly radiates outward from the original release site (Newton et al. 1994, Carter et al. 2003, see also Stamps 1988 for a similar pattern in lizards). Conservation of such species may be better approached through many, stepping-stones release sites.

\section{ACKNOWLEDGMENTS}

We thank B. Doligez, F. Hiraldo, J. Walters, and two anonymous referees for comments on a previous draft of the manuscript, and L. Marchesi and C. Scandolara for help with the fieldwork. F. Sergio was supported by a grant of the European Community-Access to Research Infrastructure Action of the Improving Human Potential Programme in Doñana Biological Station.

\section{Literature Cited}

Blas, J. 2002. Edad y reproducción en el Milano Negro (Milvus migrans). Dissertation. University of Madrid, Madrid, Spain.

Boulinier, T., and E. Danchin. 1997. The use of conspecific reproductive success for breeding patch selection in terrestrial migratory species. Evolutionary Ecology 11:505517.

Boulinier, T., and J. Lemel. 1996. Spatial and temporal variations of factors affecting breeding habitat quality of colonial birds: some consequences for dispersal and habitat selection. Acta Oecologica 17:531-552.

Buckley, N. 1997. Spatial-concentration effects and the importance of local enhancement in the evolution of colonial breeding in seabirds. American Naturalist 149:1091-1112.

Bustamante, J., and F. Hiraldo. 1990. Adoptions of fledglings by Black and Red Kites. Animal Behaviour 39:804-806.

Carter, I., A. V. Cross, A. Douse, K. Duffy, B. Etheridge, P. V. Grice, P. Newbery, D. C. Orr-Ewing, L. O'Toole, D. Simpson, and N. Snell. 2003. Re-introduction and conservation of the red kite (Milvus milvus) in Britain: current threats and prospects for future range expansion. Pages 407-416 in D. B. A. Thompson, S. M. Redpath, A. H. Fielding, M. Marquiss, and C. A. Galbraith, editors. Birds of prey in a changing environment. Scottish Natural Heritage, Edinburgh, UK.

Crawley, M. J. 1993. GLIM for ecologists. Blackwell Science, Oxford, UK.

Danchin, E., T. Boulinier, and M. Massot. 1998. Conspecific reproductive success and breeding habitat selection: implications for the study of coloniality. Ecology 79:24152428.

Danchin, E., D. Heg, and B. Doligez. 2001. Public information and breeding habitat selection. Pages 243-258 in J. Clobert, E. Danchin, A. A. Dhondt, and J. D. Nichols, editors. Dispersal. Oxford University Press, Oxford, UK.

Doligez, B., C. Cadet, E. Danchin, and T. Boulinier. 2003. When to use public information for breeding habitat selection? The role of environmental predictability and density dependence. Animal Behaviour 66:973-988.

Doligez, B., E. Danchin, and J. Clobert. 2002. Public information and breeding habitat selection in a wild bird population. Science 297:1168-1170.

Forero, M. G., J. A. Donázar, J. Blas, and F. Hiraldo. 1999. Causes and consequences of territory change and breeding dispersal distance in the Black Kite. Ecology 80:12981310.

Forero, M. G., J. A. Donázar, and F. Hiraldo. 2002. Causes and fitness consequences of natal dispersal in a population of Black Kites. Ecology 83:858-872.

Green, E. 1987. Individuals in an osprey colony discriminate between high and low quality information. Nature 329: 239-241.

Hiraldo, F., J. P. Veiga, and M. Mañez. 1990. Growth of nestling black kites Milvus migrans: effects of hatching

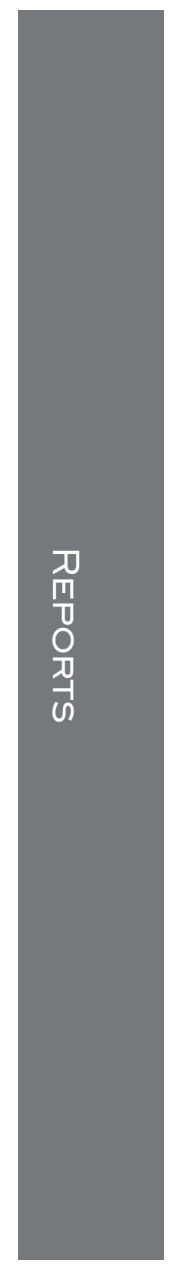


order, weather and season. Journal of Zoology, London 222: 197-214.

Hooge, P. N., and B. Eichenlaub. 1997. Movement. Animal movement extension to ArcView version 1.1. Alaska Biological Science Center, U.S. Geological Survey, Anchorage, Alaska, USA.

Liberatori, F., and V. Penteriani. 2001. A long-term analysis of the declining population of the Egyptian Vulture in the Italian peninsula: distribution, habitat preference, productivity and conservation implications. Biological Conservation 101:381-389.

Marchesi, L., F. Sergio, and P. Pedrini. 2002. Costs and benefits of breeding in human-altered landscapes for the Eagle owl Bubo bubo. Ibis 144:164-177.

Muller, K. L., J. A. Stamps, V. V. Krishnan, and N. H. Willits. 1997. The effects of conspecific attraction and habitat quality on habitat selection in territorial birds (Troglodytes aedon). American Naturalist 150:650-661.

Newton, I., P. E. Davis, and D. Moss. 1994. Philopatry and population growth of red kites, Milvus milvus, in Wales. Proceedings of the Royal Society of London Series B 257: 317-323.

Perrins, C. M., and P. J. Jones. 1974. Inheritance of clutch size in the Great Tit (Parus major L.). Condor 76:225-229.

Ray, C., M. Gilpin, and A. T. Smith. 1991. The effect of conspecific attraction on metapopulation dynamics. Biological Journal of the Linnean Society 42:123-134.

Reed, J. M., T. Boulinier, E. Danchin, and L. W. Oring. 1999. Informed dispersal: prospecting by birds for breeding sites. Current Ornithology 15:189-259.

Rice, W. R. 1989. Analyzing tables of statistical tests. Evolution 43:223-225.

Schiek, J., and S. H. Hannon. 1992. Territory and male quality do not influence settlement of yearling female Willow Ptarmigan. Behavioral Ecology 3:148-155.

Sergio, F. 2003a. From individual behaviour to population patterns: weather-dependent foraging and breeding performance in black kites. Animal Behaviour 66:1109-1117.

Sergio, F. 2003b. Relationship between laying dates of Black Kites and spring temperatures in Italy: rapid response to climate change? Journal of Avian Biology 34:144-149.

Sergio, F., and A. Boto. 1999. Nest dispersion, diet, and breeding success of Black Kites (Milvus migrans) in the Italian pre-Alps. Journal of Raptor Research 33:207-217.
Sergio, F., L. Marchesi, and P. Pedrini. 2003a. Spatial refugia and the coexistence of a diurnal raptor with its intraguild owl predator. Journal of Animal Ecology 72:232-245.

Sergio, F., L. Marchesi, and P. Pedrini. 2004a. Integrating individual habitat choices and regional distribution of a biodiversity indicator and top predator. Journal of Biogeography 31:619-628.

Sergio, F., L. Marchesi, P. Pedrini, M. Ferrer, and V. Penteriani. 2004b. Electrocution alters the distribution and density of a top predator, the eagle owl Bubo bubo. Journal of Applied Ecology 41:836-845.

Sergio, F., and I. Newton. 2003. Occupancy as a measure of territory quality. Journal of Animal Ecology 72:857-865.

Sergio, F., P. Pedrini, and L. Marchesi. 2003b. Reconciling the dichotomy between single species and ecosystem conservation: black kites (Milvus migrans) and eutrophication in pre-Alpine lakes. Biological Conservation 110:101-111.

Sergio, F., P. Pedrini, and L. Marchesi. 2003c. Spatio-temporal shifts in gradients of habitat quality for an opportunist avian predator. Ecography 26:243-255.

Sergio, F., P. Pedrini, and L. Marchesi. 2003d. Adaptive selection of foraging and nesting habitat by black kites (Milvus migrans) and its implications for conservation: a multiscale approach. Biological Conservation 112:351-362.

Serrano, D., J. L. Tella, M. G. Forero, and J. A. Donázar. 2001. Factors affecting breeding dispersal in the facultatively colonial lesser kestrel: individual experience vs. conspecific cues. Journal of Animal Ecology 70:568-578.

Sokal, R. R., and F. J. Rohlf. 1981. Biometry. W. H. Freeman, New York, New York, USA.

Stamps, J. A. 1987. Conspecifics as cues to territory quality: a preference of juvenile lizards (Anolis aeneus) for previously used territories. American Naturalist 129:629-642.

Stamps, J. A. 1988. Conspecific attraction and aggregation in territorial species. American Naturalist 131:329-347.

Stamps, J. A. 1994. Territorial behavior: testing the assumptions. Advances in the Study of Behavior 23:173-232.

Tabachnick, B. G., and L. S. Fidell. 1996. Using multivariate statistics. HarperCollins, New York, New York, USA.

Valone, T. J. 1989. Group foraging, public information, and patch estimation. Oikos 56:357-363.

\section{APPENDIX A}

A figure showing the location of the Black Kite study areas is available in ESA's Electronic Data Archive: Ecological Archives E086-016-A1.

\section{APPENDIX B}

A figure showing the breeding performance since the first year of territory occupation is available in ESA's Electronic Data Archive: Ecological Archives E086-016-A2. 